\title{
(Under)specification of the person feature in relative clauses
}

\author{
Kaori Furuya \\ University of North Texas \\ Kaori.Furuya@unt.edu
}

\begin{abstract}
By examining $\phi$-agreement in relative clauses, this paper investigates the relation between syntax and morphology in terms of the person feature. English relativized subjects appear to have different phi-features for the purposes of subject-verb agreement and binding relations. The verbal morphology uniformly displays 3rd person whereas reflexive binding shows 1st/2nd person in addition to 3rd person. If subject extraction must trigger an invariable verbal form as Ouhalla (1993) argues, the binding alternations cannot be accounted for. This paper proposes dual properties of the person feature based on Harley and Ritter's (2002) feature geometry, and argues that relativized subjects may not obtain both properties of the person feature from the head noun via Agree. This partial agreement causes morphosyntactic variation in English and cross-linguistically in Distributed Morphology (DM). The current analysis demonstrates that referential and morphological (under)specifications are kept separate under the constraint of the syntactic operation Agree.
\end{abstract}

Keywords: anti-agreement effect; binding; relatives; (under)specification; person feature; Distributed Morphology

\section{Introduction}

Normally subject-verb agreement and reflexive binding uniformly exhibit the same morphosyntactic specification. The $\phi$-values of the subject are morphologically realized equally on the verbal morphology in subject-verb agreement and on the reflexive bound by the subject. Any mismatch in $\phi$-agreement results in ungrammaticality. However, this is not always the case. When the head noun is a 1st or 2 nd singular pronoun (a scenario that makes it possible to decide if syntactic person agreement has applied or not), the verbal morphology is always invariable, whereas reflexives exhibit the pronominal alternations in (1) (Ross 1970; Nelson 1997; Sornicola 1988). ${ }^{1}$

${ }^{1}$ Akmajian $(1970,153)$ discusses three dialects, only one of which shows 1st person agreement in verbal morphology as in (i) below (see also Heck \& Cuartero 2008; Ross 1970; section 2): 
(1) a. It is me who has always kept myself/himself out of trouble.

b. It is me who has to protect myself/himself.

c. It is $\{\mathrm{me} / \mathrm{I}\}$ who is looking at myself/himself.

d. It is you who is making fun of yourself/himself.

(Akmajian 1970, 156)

The verbal morphology is always 3rd person, but reflexives may have 1st/2nd person in addition to 3rd person. This example in (1) shows that the realization of verbal morphology and reflexives is not necessarily identical in terms of the person feature. We should notice that selecting a 1 st $/ 2$ nd or 3rd person reflexive does not change the meaning and the pairs have identical truth conditions.

Interestingly, the dissociation of subject-verb agreement and binding agreement in terms of the person feature is also observed even when the head noun is not a 1 st or 2 nd person pronoun, as in (2). ${ }^{2}$

(2) a. I am the one that is proud of myself/himself.

(Adger 2011, 356)

b. I am the one who has to project myself.

(Akmajian 1970, 158)

c. I am a person who is comfortable with myself.

(Collins \& Postal 2012, 177)

d. You are an experienced teacher who takes care of himself/yourself.

(ibid., 159)

Even when the personal pronoun is not adjacent to the relativized subject, the sentences exhibit the pronominal alternations in binding while the verbs are uniformly $3 \mathrm{rd}$ person. These mismatches in person agreement are puzzling.

The important question for this article is how the verbal morphology uniformly shows $3 \mathrm{rd}$ person while at the same time reflexives can be 1st or 2nd person. Do the relativized subjects possibly possess the person feature? Alternatively, do the verbs fail to morphologically realize the person feature via subject-verb agreement? Setting aside theoretical considerations for a moment, let us consider two logical perspectives on the verbal morphology of the English subject-verb agreement phenomenon, listed in (3).

(i) a. It is I who $\left\{\mathrm{am},{ }^{*}\right.$ is $\}$ responsible.

b. It is me who $\{$ is, $*$ am $\}$ responsible.

The example that is associated with Case in (ia) is beyond the current focus.

${ }^{2}$ For some reason, number agreement appears to be optional in the relative clauses in (i) (see also section 2):

(i) a. We are a team that outdoes ourselves/themselves.

(Collins \& Postal 2012, 183-184)

b. We are the ones that are proud of ourselves/themselves. (Adger 2011, 356)

The analysis of number is beyond the scope of this paper. 
(3) a. Relativized subjects are underspecified for the person feature, and hence cause the verbal morphology to be in an invariable form.

b. The verbal morphology fails to exhibit agreement in the person feature.

The statement in (3a) is the main argument that Ouhalla (1993) offers in his study of the underspecification of the verbal morphology associated with subject extraction, called the anti-agreement effect (AAE). Since his study of the invariable verbal morphology, suppression of the verbal morphology has been widely researched in line with (3a) within the generative literature (Grohmann 2003; Baker 2008; Henderson 2013; Ouhalla 2005; Schneider-Zioga 2007; van Urk \& Richards 2015, among others). However, the line of analysis in (3a) would predict that similarly to what we see in the case of the verbal morphology, 1st or 2nd person should not appear in reflexive binding either, as the subjects lack the relevant features. Yet, this is contrary to what we observe in (1) and (2). Instead of the relativized subject being the cause, one may assume that the verbal morphology itself is prevented from showing agreement and remains underspecified in (3b). If this is the case then the failure of realizing the 1st or 2nd person verbal morphology would indicate that referential and morphological (under)specifications of the person feature are kept separate. Yet one needs to find out how the verbal morphology is suppressed in subject-verb agreement while the binding relations do not necessarily show the same featural underspecification at the same time. ${ }^{3}$

Given an Agree analysis proposed by Chomsky (2000; 2001), this paper argues that relativized subjects are featureless and obtain $\phi$-features from the head noun under an agreement relation (Landau 2015). The person feature that the verbs obtain via subject-verb agreement fails to be morphologically realized at PF due to the dual properties of the person feature (notional and grammatical person), in support of the statement in (3b). The dual properties of the person feature also cause morphosyntactic variation in English reflexive binding and in Bemba and Spanish relatives.

The present paper is organized as follows. Section 2 presents evidence for 3rd person as the invariable verbal morphology and argues that 3rd person may be taken to be the default person in English. Section 3 applies three major analyses of the underspecified verbal morphology to the English relatives in (1) and (2). It shows that these analyses fail to account for binding agreement in the contexts of the invariable verbal morphology. Section 4 proposes the person feature with the dual properties (notional and grammatical person) based on the perspectives of the person

\footnotetext{
${ }^{3}$ Clefts and restrictive relatives as in (1) and (2) are treated uniformly in this paper.
} 
feature presented in Harley and Ritter's (2002) feature geometry and the observations of definite DPs offered by Collins and Postal (2012). Section 5 implements the formulation of agreement relations with the generalized person feature geometry in the framework of Agree and DM. It argues that relativized subjects obtain the person feature from a personal pronoun in the matrix clause and yet may lack grammatical person, which induces morphosyntactic variation post-syntactically in English and cross-linguistically. Section 6 is the conclusion.

\section{The 3rd person feature as the default feature in English}

Ouhalla (1993, 477) argues that "the verb cannot agree with the locally extracted subject; instead, the verb has an invariable (3rd person singular) form". He observes that the default/neutral form may be 3rd person or another invariable form cross-linguistically. The 3rd person form of the verbs in (1) and (2) may be identified as an invariable form, i.e., Ouhalla's AAE, in the contexts of subject extraction. This perspective receives support from Baker's (2011) observation of some dialects of English.

According to Baker (2011), in certain nonstandard dialects of English discussed by Kimball and Aissen (1971) and Kayne (2000), the finite verb can show agreement with a relative pronoun in number but not in person (4).

(4) a. 'the people who Clark are hoping are in the garden

b. the person who Clark think*(s) is in the garden

c. 'we who Clark are hoping will come

d. *I who Clark am hoping am in the garden

(Baker 2011, 887)

In (4a) the form of the copula that would be expected in agreement with the subject Clark is is, but the plural form are is possible, agreeing with the $w h$-word who, which in turn agrees with the 3rd person plural head of the relative clause, people. (4b) confirms that this is a form of agreement, not just the optional omission of a morpheme, because think is not possible when the wh-word is 3rd person singular. (4c) also shows the same agreement phenomenon that the verb be can agree with such an element in number, showing up as are rather than is. But (4d) shows that the verb be cannot agree with the head of the relative in the person feature; the 1st person singular form am is clearly impossible in this environment for speakers of any (known) variety. Crucially, this example shows that the finite verb cannot display agreement in person. Baker takes the 3rd person 
form to be the default feature in English. This suggests that the unvalued person feature is morphologically illicit and tolerated with the realization of 3rd person only as a last resort in English.

Heck and Cuartero (2008) offer further supporting observations regarding 3rd person in subject-verb agreement in English. According to them, native speakers of some dialects of English use subject-verb agreement when the 1st person pronominal subject is nominative (5a); otherwise they allow the verb to be 3rd person in a context of long relativization $(5 \mathrm{~b}){ }^{4}$

(5) a. It is I who am responsible.

(Heck \& Cuartero 2008, 14)

b. It is I who John says is sick.

(ibid., 42)

The copula in the relative clause is $a m$ in $(5 a) .{ }^{5}$ In contrast, the copula in (5b) is is when the relativization is not local. ${ }^{6}$ What is relevant here is that Heck and Cuartero likewise view 3rd person in (5b) as the default person in English. Furthermore, they also report that some speakers accept 3rd person singular even when the relative head is plural (6).

(6) a. 'It is us who is responsible.

b. 'It is them who is responsible.

(ibid., 29)

${ }^{4}$ The speakers that allow (5a) belong to the 3rd group among the three groups in Akmajian (1970).

${ }^{5}$ Heck and Cuartero (2008) analyze the dialect that shows the 1st person verbal morphology in English relatives (see footnote 1) and argue that $\mathrm{T}$ and $\mathrm{C}$ establish Agree within a relative. $\mathrm{C}$ obtains $\phi$-values from the head noun and shares it with $\mathrm{T}$. According to Heck and Cuartero, this process of Agree stems from a constraint that requires valuation of the person feature to go hand in hand with coalescence of nominative Case in this dialect. One may assume that other dialects of English lack such a constraint relating to Case.

${ }^{6}$ Heck and Cuartero $(2008,42)$ also report that infinitives in Portuguese show a similar pattern in featural specification (i):

(i) a. Vios cavalos * *orer/correrem.

saw the horses run/run.3PL

'I saw the horses run.'

b. os cavalos que vi corer $/ *$ correrem

the horses REL saw run/run.3PL

'the horses that I saw run'

(Perlmutter 1972, 88)

The infinitive that is embedded under verbs of perception, such as 'to see', obligatorily agrees with the thematic subject in (ia). However, $\phi$-agreement between the subject and the verb is barred in (ib). Heck and Cuartero argue that underspecication of verbal morphology appears when $\phi$-agreement is prevented by the vP-boundary. 
Regardless of the $\phi$-features of the head noun, the sentences uniformly exhibit 3rd person verbal agreement. These examples indicate that 3rd person is an invariable form in English relative clauses. Ouhalla (1993) treats 3rd person as the default person in Breton, Fiorentino, Trentino, Turkish, and Welsh, too. ${ }^{7}$ (Note that this paper is not concerned with the number-mismatch phenomenon.) However, the treatment of the English 3rd person verbal morphology as an AAE appears to be problematic to the pronominal alternations in (1) and (2) because the binding relations can exhibit 1st/2nd person in addition to 3rd person. One wonders how the underspecification of subject-verb agreement can be associated with the featural specification in binding inside relative clauses.

Instead of treating subject-verb agreement and binding agreement as the same syntactic phenomenon, one might assume that binding relations are outside narrow syntax, as the canonical Minimalist binding theory views the Binding Conditions as interpretive rules applying at LF (Chomsky 1993; Chomsky \& Lasnik 1993). If this were the case, subject-verb agreement and binding agreement should be dissociated, and the uniform treatment of both types of agreement in proper syntax should be wrong. However, the pronominal alternations as well as the dissociation of subject-verb agreement and binding agreement are not normally found in pronominal binding. The distinct treatment of both types of agreement cannot account for the agreement relations in (7).

(7) a. I $\left\{*_{\text {is }} /\right.$ am $/ *$ are $\}$ looking at myself $/ *$ himself.

b. You $\{*$ is $/ *$ am $/$ are $\}$ looking at yourself $/ *$ himself.

c. The man $\{$ is $/ *$ am $/ *$ are $\}$ looking at $*$ myself $/ *$ yourself $/$ himself.

${ }^{7}$ Two remarks are in order. First, Ouhalla (1993) assumes that 3rd person is the default or neutral form when the verbal morphology is also singular, even though the extracted subject is plural, as in (i):

(i) Quante putele ha parla con $t_{i}$ ?

'How many girls (it) has spoken to you?'

(Trentino; Ouhalla 1998, 481 citing Brandi \& Cordin 1989, 139)

Ouhalla's way of identifying 3rd person as the default form in relation to the number feature may not be accurate since there are languages that show number agreement but not person agreement. Henderson (2013) and Baker (2008; 2011) present relevant data cross-linguistically.

Second, this paper is not concerned with the number-mismatch phenomenon, although it appears that number and person are associated with each other for specification (Nevins 2011). 
They exclusively exhibit the same values of the person feature for both the purposes of subject-verb agreement and binding relations. For example, a 1st person pronoun in (7a) only displays the 1st person agreement relation with the verb and correspondingly is only compatible with a 1st person reflexive; the other forms are ungrammatical. This fact shows that subject-verb agreement and binding agreement are generally compatible with each other in syntax. Moreover, recent Minimalist research proposes that reflexive binding relations fall in narrow syntax, as Condition A can be reduced to an application of the Agree operation employed in Chomsky's $(2000 ; 2001 ; 2007 ; 2008)$ framework, supplying the missing values of bound objects (Fischer 2004; 2006; Lee-Schoenfeld 2008; Quicoli 2008; Hicks 2009; Kratzer 2009; Furuya 2009; 2016b; 2017; Despić 2015; Reuland 2011; Rooryck \& Vanden Wyngaerd 2011; Safir 2014, among others). Based on recent research on Condition A via Agree and on the observations in this section, I assume that subject-verb agreement and reflexive binding are equally constrained by the syntactic operation Agree as a feature-sharing operation. Moreover, I take the 3rd person feature of the verbal morphology that appears with 1st and 2nd person head nouns as the default person form.

Once the two types of agreement in binding and subject-verb relations are uniformly treated in narrow syntax, how can the dissociation of the two types in person specification come about in English relatives? In the following section I apply three major analyses of AAEs to English relative clauses and examine whether any of them is able to account for the morphosyntactic variation.

\section{Previous accounts of the anti-agreement effects}

Many languages that normally show verbal agreement with the subject in a designated position eschew agreement when the subject is extracted. ${ }^{8}$ I review three major analyses of AAEs offered by Ouhalla (1993), Baker (2008), and Henderson (2013) in 3.1-3.3. Although these studies focus only

${ }^{8}$ AAE has been discussed in a variety of languages including Abaza (O'Herin 2002), Bemba (Cheng 2006; Henderson 2013), Berber (Ouhalla 1993; 2005; Ouali 2008), Breton (Hendrick 1988), Celtic (Borsely \& Stephens 1989), Chamorro (Chung 1998), Dinka (van Urk \& Richards 2015), Ibibio (Essien 1990; Baker 2008), Kinande (SchneiderZioga 1995; 2000; 2007), Lubukusu (Diercks 2010; 2013), Palauan (Georgopoulos 1991) Turkish (Ouhalla 1993; Kornfilt 1991), Welsh (Hendrick 1988; McCloskey 1990), Yimas (Phillips 1996), and the Italian dialects of Fiorentino and Trentino (Brandi \& Cordin 1989). 
on the underspecification of verbal morphology, I apply them to English relatives that display the invariable verbal morphology and the binding alternations at the same time. These three analyses propose that the underspecification of the verbal morphology comes about by suppressing the $\phi$-features of extracted subjects. However, I show that the suppression of $\phi$-values of relativized subjects fails to fully account for the English data. In this paper I only focus on relativized subjects, although I also mention interrogative subjects in this section and analyze the distinction between interrogative and relativized subjects in section 6 .

\subsection{Ouhalla's (1993) trace analysis}

Ouhalla (1993) presents data for AAEs in the contexts of subject-extraction from Berber, Celtic, Fiorentino and Trentino, and Turkish. According to Ouhalla, wh-words are base-generated either in the subject position or in Spec, CP. In the former case, they are moved to Spec, CP, leaving a variable trace behind, whereas in the latter case a resumptive pro appears in the subject position. He argues that the original loci of $w h$-words are closely related to the AEE. Extraction of a(n) interrogative or relativized subject gives rise to an obligatory AAE because the trace of a moved $w h$-subject does not have to be licensed by the "rich" verbal morphology and it satisfies the ECP by being governed by the C head. On the other hand, a resumptive pro in the subject position needs to be licensed by the verbal morphology and thus the AAE is not displayed in this case.

Given the two types of $w h$-words, Ouhalla (1993) proposes that Berber $w h$-subjects undergo movement. His analysis of $(8 \mathrm{a})$ is shown in $(8 \mathrm{~b}) .{ }^{9}$

(8) a. tamghart-a ay yzrin/*t-zara Mohand.

woman this COMP saw/3fs-saw Mohand

'It was this woman who saw Mohand.'

(Berber; Ouhalla 1993, 479)

b. DP [CP $w h_{i}\left[\mathrm{IP} t_{i}\right.$ v-anti-agreement...]]

The verbal agreement morphology $t$ - is suppressed in the relative clause in (8a). Ouhalla $(1993,489)$ argues that a variable trace exists in the subject position once a (covert) relative pronoun is moved to Spec, CP (8b). This trace in the subject position is governed by the $\mathrm{C}$ head and it does not have to be licensed by the verbal morphology, resulting in the AAE.

${ }^{9}$ Ouhalla (1993) treats both interrogative and relativized subjects as wh-elements, even though there is no overt element for relative pronouns in Berber, Celtic, and Turkish. 
However, Ouhalla's (1993) analysis cannot apply to English relatives because English may show binding agreement as in (1a), repeated as (9a) with its schema in $(9 \mathrm{~b})$.

(9) a. It is me who has always kept myself/himself out of trouble.

b. It is [DP me [CP $\mathrm{Who}_{i}\left[t_{i}\right.$ v-anti-agreement myself/himself $\left.]\right]$

Under Ouhalla's analysis, the trace of the subject is a variable and thus the verbal morphology is underspecified. If, however the trace in the subject position is "invisible" to the verb for agreement, it should not be "visible" to its bound pronoun either. Selecting a 1st person reflexive should be ungrammatical in (9), contrary to fact. Notice that an element in CP cannot bind anaphoric expressions in (10) (e.g., Chomsky 1993; Chomsky \& Lasnik 1993).

(10) a. Which boy ${ }_{i}$ does it seem (*to himself ${ }_{i}$ ) that Mary loves $t_{i}$ ? (Kobele 2010, 147)

b. ${ }^{*}$ Who $_{i}$ does [each other ${ }_{i}$ 's supporters] like $t_{i}$ ?

The fact that the wh-word in CP cannot bind himself in (10a) and each other in (10b) confirms that a reflexive must be locally A-bound (not A-bar bound), as Condition A states. Likewise, the relativized subject who in $\mathrm{CP}$ cannot bind the reflexive in (9a). ${ }^{10}$ Hence it is unlikely that Ouhalla's resumptive pro can account for the presence of 1 st or 2 nd person on reflexives, although the trace analysis may explain the invariant verbal form in English relatives.

\subsection{Baker's (2008) copy and deletion analysis}

Baker (2008) analyzes AAEs as copy and deletion of $\phi$-features, based on the data from Ibibio, a Niger-Congo language spoken in southeastern Nigeria (Essien 1990). In this language the prefix $a^{-}$, the $3 \mathrm{rd}$ person verbal morphology, is not selected in the presence of interrogative and relativized subjects (11).

(11) a. Okon a-kere ke anie i-di-dep ebot rnkporj? (*a-ya-dep) Okon 3rd-think C ([-wh]) who I-FUT-buy goat tomorrow 3rd-C-buy 'Who does Okon think will buy a goat tomorrow?'

(Baker 2008, 617)

${ }^{10}$ One reviewer asks whether the head noun me may be the potential antecedent in (9b). Taking the head noun to be the binder would violate locality requirements because pro (as well as who) is the closer potential candidate. 
b. Ami m-ma-kit ebot se i-k-i-ta udia. (*a-ke-ta)

I 1st-PAST-see goat that I-PAST-I-eat yam 3rd-C-eat

'I saw the goat that ate the yams.'

(ibid., 621)

In interrogative and relative clauses such as (11), the AAE marker verbal prefix $i$ - is used instead of $a-.{ }^{11}$ Importantly, the interrogative subject in (11a) occurs at a lower position than the complementizer $k e$ and yet the AAE is observed. Baker argues that the interrogative and relativized subjects in (11) do actually undergo movement. Taking up proposals by Fox and Nissenbaum (1999) and Bobaljik (2002) that there is covert movement with spell-out of a lower copy, Baker assumes that there is a process of Feature Deletion in a chain, although he admits that his assumption is nonstandard in the Minimalist literature. Let us consider Baker's analysis using the schema with the distribution of the $\phi$-features in (12) for the example in (11b).

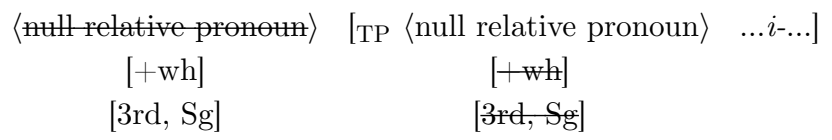

Under Baker's copy deletion analysis, when a wh-movement chain is transferred to the interfaces, an operation called Feature Deletion removes the phonological and semantic features from the two copies differently (12). In the higher copy the phonological features are deleted whereas the semantic features are kept. On the other hand, in the lower copy the semantic features are deleted, while the phonological features are maintained. In Baker's theory deleting the features of the lower copy results in the AAE.

${ }^{11}$ Baker $(2008,628)$ additionally reports that the AAE also appears with negation in Ibibio, even when there is no extraction of the subject (i) (Bokamba 1976 for Dzamba):

(i) a. ommo: í-k-i-di-ghe. (*e-ke-di-ghe)

they I-PAST-I-come-NEG

'They did not come.'

b. Afit owo i-k-i-dia-gha ekpay.

all person I-PAST-I-eat-NEG porridge

'Not all of the people ate porridge.' (not: $[\forall x$ person $(x)$ [ $x$ eat porridge $]$ )

In (ia) there is no A-bar movement, covert or overt, in the examples with negation. Yet, the same anti-agreement form $i$ - should be used in this context. Baker remarks that the subject of a negative clause in (ib) takes narrow scope with respect to negation. 
However, there is a puzzling issue with the Ibibio examples in Baker's (2008) analysis. There is no evidence that the interrogative subject (that occurs in a lower position than the complementizer) moves covertly to CP in (11), even though this point is crucial to Baker's analysis. Chomsky (2000; 2001) claims that covert movement in the syntactic module should be rejected (see Watanabe 2006; Munakata 2006 for supporting arguments, and Morita 2009 for support of the covert movement analysis).

Furthermore, his analysis of copy deletion fails to generalize to English relatives in (1) and (2), whose schema is illustrated in (13).

(13) $[\ldots$ pronoun $(\ldots)[$ CP relative pronoun $[\mathrm{TP}$ relative pronoun... $\mathrm{V}$ - anti-agreement $\ldots$ reflexive] $\{1$ st $/ 2$ nd $\} \quad\{1$ st $/ 2$ nd $\} \quad\{1$ st $/ 2$ nd $\}$

Provided that the relative pronoun in (13) obtains the person feature from the pronoun in the matrix clause via agreement (see section 5), under Baker's analysis the lower copy in TP deletes the person feature in order to suppress subject-verb agreement. However, this analysis faces the same problem as Ouhalla's (1993) trace analysis. The relative pronoun in TP lacks the person feature and thus it cannot bind a 1st/2nd person reflexive. Moreover, the higher copy is located in $\mathrm{CP}$ and thus cannot function as a binder either. Thus, Baker's analysis also fails to extend to English relatives.

\subsection{Henderson's (2013) referential feature analysis}

Henderson $(2009 ; 2013)$ observes that AAEs are not realized as 3rd person in Bantu languages. Instead, these languages show a distinct invariable morphology in the absence of $\phi$-features for agreement, as is also observed in Ibibio by Baker (2008). Henderson notes that Bantu AAEs uniquely affect the realization of the person feature (see also Kinyalolo 1991; Ouhalla 1993; 2005). Consider the example in (14).

$$
\begin{aligned}
& \text { u-mulumendo ú-u-ka-belenga ibuku (*ú-a-ka-belenga) } \\
& \text { 1-boy 1REL-AAE-FUT-read 5book 1REL-3SG-fut-read } \\
& \text { 'the boy who will read the book' （Bemba; Henderson 2013, 455) }
\end{aligned}
$$

The verb in (14) exhibits the AAE: the morpheme - $u$ - appears after the relative marker (REL) (i.e., ú-). Here the selection of the canonical agreement morpheme $a$ - (3rd person) is ungrammatical. Henderson $(2013,461)$ argues that when a subject XP is extracted from Spec, TP to Spec, CP, the $\phi$-features in $\mathrm{T}$ must come into agreement with those in $\mathrm{C}(15)$. 
(15)

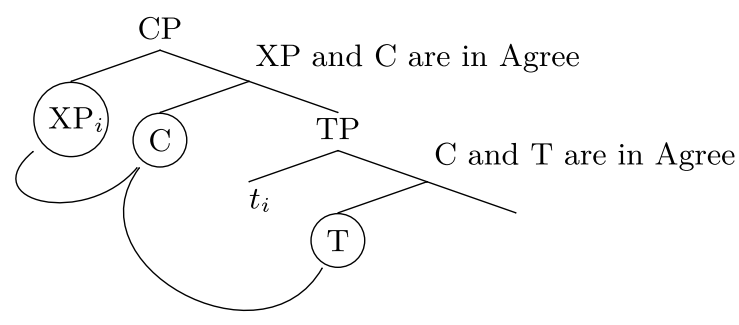

(Henderson 2013, 469)

According to Henderson, the $\phi$-features in $\mathrm{C}$ involve a referential feature \{ref\} but no person feature. Instead $\mathrm{T}$ does have a \{person\} feature, but $\{$ ref $\}$ in C "overwrites" person in $\mathrm{T}$ when the latter agrees with the former. This is the mechanism that underlines AAEs.

(16) $\mathrm{T}:\{$ person $\},\{$ number $\},\{$ class $\}$

C: $\{$ ref $\},\{$ number $\},\{$ class $\}$

In (16) the $\phi$-features in $\mathrm{T}$ remain active and therefore they can be be (re-)valued by the $\phi$-features in $\mathrm{C}$ even though they have already been valued by the inherent $\phi$-features of the subject XP. Thus, the verb in T "ultimately" agrees with the $\mathrm{C}$ head, which has a specification for referentiality $\{$ ref $\}$ but not for person. This $\{$ ref feature results in a special invariable form of the verb, the AAE, in Bantu.

However, Henderson's (2013) analysis of the C head's "overwriting" is also problematic in applying to English relative clauses. If $\{$ ref $\}$ in $\mathrm{C}$ overwrites the person feature value in $\mathrm{T}$ and suppresses the verbal morphology in subject-verb agreement, the morphological specification of reflexives should also be suppressed in relative clauses if an Agree relation holds for subject-verb agreement and reflexive binding at the same time. In this case a reflexive should be only 3rd person by default,and 1st or 2nd person reflexives should not be licensed. As an alternative, one might assume that subject-verb agreement and reflexive binding may not hold at the same time provided that $\mathrm{T}$ may somehow have either 1st/2nd person or $\{$ ref\} in the midle of a derivation. When the reflexive pronoun enters into an Agree relation with a reflexive, $\mathrm{T}$ involves 1 st or 2 nd person. Once $\mathrm{T}$ obtains $\{$ ref $\}$ from $\mathrm{C}$, it Agrees with the verb. However, this distinct timing of Agree relations still fails to account for the grammaticality of 1st person reflexives in (1), since it is not clear how the relative pronoun in TP could have a 1st person specification. Instead of timing, one might assume that the "overwriting" operation applies in English relatives optionally. Given this stipulation, if the $\mathrm{C}$ head obtains the relevant person feature value 
from the head noun and shares it with the T head without "overwriting" the value of the person feature with $\{$ ref\}, the realization of 1 st or 2 nd person on reflexives might be accounted for in English relatives. However, the optionality of the process cannot account for the underspecification of the verbal morphology that appears simultaneously. Thus, Henderson's analysis of the referential feature in CP also fails to fully account for $\phi$-agreement in English relatives.

I applied the three major analyses of AAE offered by Ouhalla's (1993) trace analysis, Baker's (2008) copy deletion analysis, and Henderson's (2013) \{ref\} analysis to $\phi$-agreement in English relatives. What is common to these analyses is that they attribute the underspecification of the verbal morphology to relativized subjects, as they take the features of subjects "invisible" or "deletable", which means that their $\phi$-values cannot be realized on verbs. If this were the case, the "invisible" relativized subjects should likewise fail to share 1st or 2nd person with their bound objects in (1) and (2), contrary to what we observed. Thus, these analyses cannot account for binding agreement in English relatives. This indicates that the perspective in (3a) appears not to be on the right track.

In the rest of this paper I examine the validity of the statement in (3b) for English relatives in (1) and (2). In the following section I generalize Harley and Ritter's (2002) feature geometry to referential DPs other than personal pronouns, and in section $5 \mathrm{I}$ apply the generalized feature geometry to $\phi$-agreement in English relatives and cross-linguistically, in favor of (3b).

\section{The person feature and binding agreement}

Before continuing the analysis of $\phi$-agreement in English relatives, I look at the properties of the person feature in the pronominal alternations: regardless of what the person feature values of the reflexives are (1st/2nd person vs. 3rd person), the meanings are the same in (1) and (2) respectively. After reviewing Harley and Ritter's (2002) analysis of the person feature, I generalize their analysis to non-personal pronouns and consider the nature of the person feature.

Harley and Ritter (2002) focus on the morphosyntactic properties of pronominal systems from a cross-linguistic perspective. They argue that the person feature depends on DPs' discourse role and propose the feature geometry in (17). 
(17) Person feature geometry

$\overbrace{\{\text { Speaker }\}\{\text { Addressee }\}}^{\text {Person }(\{\text { PARTICIPANT }\} \text { in Harley and Ritter's term })}$
(Harley \& Ritter 2002, 486)

In (17) the participant node and its dependents, Speaker and Addressee, are used to represent the person feature values in syntax. For example, a 1st person pronoun $I$ would involve $\{$ Speaker\}; a 2nd person you would have the feature \{Addressee\}. Notice that in Harley and Ritter's feature geometry notional person (i.e., the semantic category such as \{Speaker\}) and grammatical person (which refers to morphosyntactic properties associated with particular notional person forms such as $\{1$ st $\}$ ) are identical for pronominal systems.

However, Collins and Postal (2012) observe that non-pronominal DPs behave like personal pronouns in that they can be used to refer to the speaker or the addressee, just like 1st/2nd person pronouns (18).

(18) a. This reporter $(=\mathrm{I})$ and his son are proud of ourselves/themselves.

(Collins \& Postal 2012, vii)

b. Your Majesty (=you) should praise yourself/herself.

(ibid., vii)

c. Jerome and Daddy $(=\mathrm{I})$ are enjoying ourselves/themselves on the beach.

(ibid., 108)

d. The present authors (=we) will defend ourselves/ themselves.

(ibid., 207)

The definite DPs in the subject position refer to the speaker's group or addressee's group, and they are compatible with both a 1st/2nd person and 3rd person reflexive. Note that according to Collins and Postal (2012, vii), selecting a reflexive with a distinct person feature in (18) does not change the truth conditions. They call these specific kinds of DPs imposters. Although I do not analyze referential DPs in this paper, Collins and Postal's analysis of the person feature is relevant for the current proposal. Collins and Postal define imposter DPs as in (19).

(19) An imposter is a notionally $X$ person DP which is grammatically $Y$ person, $X \neq Y$.

$($ ibid., 5)

The definition in (19) states that notional person and grammatical person may be distinct in the imposter construction. For instance, the present authors in (18a) notionally possesses 1st person whereas grammatically it can be 3rd person. This perspective of the person feature requires us to modify Harley and Ritter's (2002) feature geometry in order to capture cases in which notional and grammatical person are not identical. I gen- 
eralize Harley and Ritter's feature geometry to DPs that are invariant in form but can have different references, and propose that these DPs possess notional person $\{$ Speaker/Addressee $\}$ and optionally also grammatical person $\{1$ st $/ 2$ nd $\}$. These relations are illustrated in (20).

(20) Generalized person feature geometry

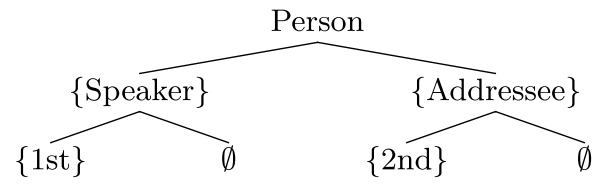

( $\emptyset$ represents the lack of grammatical person)

This generalized structure for the person feature is different from Harley and Ritter's geometry in two ways. Unlike Harley and Ritter's perspective, the present analysis assumes that notional person such as \{Speaker\} and \{Addressee $\}$ do not have to be obligatorily associated with grammatical person such as $\{1$ st $\}$ and $\{2 \mathrm{nd}\}$ respectively, although both notional person and grammatical person are taken to be syntactic objects in this paper. The second difference between Harley and Ritter's analysis and the current analysis lies in the morphological realization of 3rd person in relation to notional person. In Harley and Ritter's (ibid., 448) analysis, a 3rd person pronoun is treated as unmarked in terms of discourse roles. When no $\{$ Speaker $\}$ or $\{$ Addressee $\}$ is specified, only underspecified referring expressions (i.e., the 3rd party) are realized as 3rd person. However, in the present analysis $\{$ Speaker $\}$ or $\{$ Addressee $\}$ may be morphologically realized as 3rd person under the assumption that 3rd person is a default person in English.

Given the generalized geometry, for instance, the present authors in (18a), which refers to a speaker's group, has notional person \{Speaker\} and at the same time this DP may or may not additionally have grammatical person $\{1 \mathrm{st}\}$. When the DP has both person features \{Speaker, 1st\}, it binds a 1st person reflexive. This binding relation is the same as a binding relation with a 1st person pronoun as a binder. In contrast, when the DP in question only has notional person $\{$ Speaker, $\emptyset\}$, the DP lacks morphological information. In this case, because underspecification is illicit in English, 3rd person is selected as default person at PF. However, the morphological realization of default person varies cross-linguistically, as will be discussed in section 5. Importantly, lacking grammatical person does not induce ungrammaticality because the generalized feature geometry does not guarantee a one-to-one relation between notional and grammatical 
person on the word-level except in the case of personal pronouns. Because of this arbitrary relation, definite DPs' morphological specification of the person feature in agreement is a matter of language-specific preferences (Collins \& Postal 2012; Collins 2014; Furuya 2016b; 2017).

In addition to the dual properties of the person feature, I also assume that relative pronouns may or may not obtain grammatical person along with notional person from the head noun. Specifically, I adopt Landau's (2015) view of impoverished nominals, including relative pronouns, as shown in (21).

(21) A minimal pronoun

$X$ is a minimal pronoun iff $X=[\mathrm{D}, u \phi] .([u \phi]$ stands for unvalued $\phi$-features)

(Landau 2015, 23)

According to Landau, $X$ can be a reflexive or a relative pronoun, among others. This view of pronouns is different from that of traditional grammar, particularly in its treatment of relative pronouns: the proposed analysis views relative pronouns a featureless, whereas the traditional view takes them to have $3 \mathrm{rd}$ person. Relative pronouns are formed when the $\mathrm{C}$ head of the relative clause assigns the feature $[+w h]$ to the minimal pronoun. However, they do not originally possess the person feature value because they are not referential.

Given the assumption in (21), I propose that relative pronouns come to possess the relevant feature values in the course of the derivation (22).

(22) Relative pronouns obtain $\phi$-values via Agree.

Relative pronouns enter into an Agree relation with another nominal in order to value their own $\phi$-features, in accordance with the feature geometry in (20). ${ }^{12}$ For instance, a relative pronoun comes to possess either \{Speaker, 1st $\}$ or $\{$ Speaker, $\emptyset\}$ via an Agree relation with a 1st person pronoun.

In the following section, using the generalized feature geometry, I examine the (under)specification of subject-verb agreement and binding agreement in English relatives and cross-linguistically. I argue that morphosyntactic variation in relative clauses stems from the dual properties of the person feature, in support of the perspective in $(3 \mathrm{~b})$.

${ }^{12}$ In generative grammar there are two major analyses of the internal syntax of relative clauses: head internal approaches (Chomsky 1977; Reeve 2011; Boef 2012; Furuya 2016a, among others) and head external approaches (Schachter 1973; Kayne 1994; Zwart 2000; Bianchi 1999; 2000; de Vries 2002, among others). 


\section{Agree and its morphological specification}

I analyze the (under)specification of the verbal morphology and the binding alternations in English relatives in 5.1, and Bemba and Spanish relatives in 5.2. These languages exhibit distinct morphological specifications of the person feature. I argue that relativized subjects obtain notional person and optionally grammatical person via Agree, which leads to three types of morphosyntactic variation in subject-verb agreement and reflexive binding in relatives. The analysis crucially makes use of Chomsky's Agree operation. The proposal is couched in the framework of DM.

\subsection{English relatives}

I discuss long-distance reflexive binding under Agree before scrutinizing English relatives. Following the gist of Landau's (2013; 2015, chapter 3) argument of a syntactic predication relation, ${ }^{13} \mathrm{I}$ assume that a relative clause is turned into a predicate when a relative pronoun is merged at its edge, and the head noun and the predicate Agree (23).

(23) In a relative construction $\left[\ldots X_{i}\left[\mathrm{CP}\right.\right.$ Relative $\left.\operatorname{pronoun}_{i} \ldots\right]$, where the referential noun $X$ is in a predicate relation with the Relative pronoun of the relative clause

a. the controller(s) $X$ must be co-dependent(s) of $\mathrm{CP}$ and

b. a relative pronoun (or part of it) must be interpreted as a bound variable.

A relativized subject obtains $\phi$-values from a referential noun because the predicate is not inherently specified for $\phi$-values. ${ }^{14}$ The $\phi$-values obtained

${ }^{13}$ Landau $(2013,29)$ discusses control and proposes the predication relation in (i):

(i) In control construction $\left[\ldots X_{i} \ldots\left[\mathrm{S} \mathrm{PRO}_{i} \ldots\right] \ldots\right]$, where $X$ controls the PRO subject of the clause $\mathrm{S}$ :

a. the controller $X$ must be (a) co-dependent(s) of S.

b. PRO (or part of it) must be interpreted as a bound variable.

According to Landau, a predicative relation is established between a referential argument and $\mathrm{S}$ as a predicate once PRO moves to CP in (i) (see Landau 2013 for details).

${ }^{14}$ One reviewer points out that syntactic predication does not obligatorily require $\phi$-feature sharing in English and cross-linguistically (e.g., Baker 2011), as in (i):

(i) a. These data are a big headache.

b. You and I are the same person.

The fact that the subject and the predicate exhibit distinct number feature values in (i) suggests that nominal predicates are independently speci- 
by the relative pronoun are shared with its lower copy in TP via Agree as feature sharing (see Pesetsky \& Torrego 2007; Landau 2015). This lower copy of the relativized subject functions as a local antecedent of a reflexive in a relative clause.

What are phases for an Agree relation? Chomsky (2000; 2001) identifies $\mathrm{vP}$ and $\mathrm{CP}$ as phases. However, it has also recently been argued that phases are determined contextually; that is, on such approaches, whether a particular projection counts as a phase largely depends on its syntactic context or environment (Chomsky 2007; 2008). ${ }^{15}$ I assume with Chomsky (2000; 2001) that CP and vP are phases. I additionally assume that elements remain in the derivation and enter a feature-sharing operation until the features get valued before the phase is sent to Spell-Out. (Landau $2000 ; 2004) .{ }^{16}$ As for the morphological realization of $\phi$-features, I adopt the framework of DM proposed by Halle and Marantz $(1993 ; 1994)$. In DM the output of a syntactic derivation is mapped to phonology through morphology, and lexical insertion happens post-syntactically by adding phonological material to the derivation after narrow syntax.

Against these background assumptions, let us look at the $\phi$-agreement relations of the English relative clause in (24a), whose schema is illustrated in $(24 b)$.

fied for $\phi$-features. However, not all elements in the predicate position inherently possess $\phi$-features from the beginning of the derivation. When it does not inhererently possess $\phi$-features, the predicate exhibits agreement, as in (ii): (ii) a. Est-as mujer-es son gord-as. these-F.PL women(F)-PL are.3pS fat-F.PL

'These women are fat.'

b. Min bytaam-myn.

(Spanish; Baker 2011, 879)

I.NOM slow-1SG

'I am slow.' (Sakha; Baker 2011, 881, originally from Vinokurova 2009, 205)

The adjectival predicates in (ii) lack $\phi$-values in the lexicon since they are not inhererently referential, and yet they are marked for $\phi$-agreement in syntax.

${ }^{15}$ Recent approaches to phases have identified other categories such as DPs, TPs, PPs and AppIP as phases (Adger 2003; Canac-Marquis 2005; Chomsky 2007; 2008; den Dikken 2007; McGinnis 2004; Rackowski \& Richards 2005; Bošković 2014, among others).

${ }^{16}$ I leave open the question of whether Cyclic Agree, Multiple Agree or some other Agree relation should be applied to the agreement relations in relatives (Béjar \& Rezac 2009; Nevins 2007; 2011). 
(24) a. It is me [who $\{$ is $/ *$ am $\}$ looking at myself/himself].

(cf., (1a))

b. $\ldots\left[\operatorname{pronoun}\{\right.$ Speaker, $1 \mathrm{st}\}\left[\mathrm{CP} \operatorname{RP}_{i}\{\right.$ Speaker,$\emptyset\}\left[{ }_{\mathrm{TP}} t_{i}\{\right.$ Speaker,,$\emptyset\}[\mathrm{vP}$ reflexive $\{$ Speaker,$\left.\left.\emptyset\}]\right]\right]$

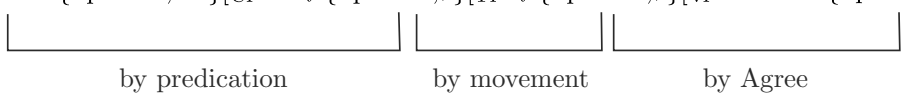

The person feature value of the relative pronoun in CP is assigned by the pronoun $m e$, and the same value is also shared with the reflexive via the $\mathrm{T}$ head. In this agreement process, I assume that even though the head noun itself possesses the features \{Speaker, 1st\}, the English relative pronoun in $\mathrm{CP}$ only receives notional person but not grammatical person: $\{$ Speaker, $\emptyset$ \}. I base this assumption on the fact that the verbal morphology in the relative invariably shows no agreement in (24a). Because underspecification is illegitimate in English, 3rd person is selected as the default person for verbal morphology post-syntactically. This partial agreement relation in person between the personal pronoun and the relative pronoun causes the underspecification of the verbal morphology, $\mathrm{AAE}$, at PF, and thus is is selected in (24a).

Why does the relative pronoun fail to receive the grammatical person feature from the head noun in (24b)? I argue that the selection of the person feature value by English relative pronouns is linked to language-specific preferences for its morphological specification at PF. Because grammatical person and notional person are not obligatorily in a one-to-one relation, the lack of sharing grammatical person is a specific property of English. The proposed account of the dual properties of the person feature predicts cross-linguistically distinct featural realizations. I will discuss this in more detail in the next subsection.

The same featural specification also applies to the reflexive in (24b). The reflexive that is bound by the lower copy of the relative pronoun in TP also obtains $\{$ Speaker, $\emptyset\}$, which is realized as 3rd person post-syntactically. In addition, I propose that this person feature value can be realized as 1st person in English because of the presence of notional person \{Speaker\}. When an element lacks grammatical person, it does not have morphological information. Yet the underspecification is illicit in English and needs to be morphologically realized at PF. Thus, $\{$ Speaker, $\emptyset\}$ is morphologically specified on the reflexive in two ways at PF, as shown in (25).

(25) Realization of an English reflexive's person feature at PF $\{$ Speaker, $\emptyset\} \rightarrow 1$ st or 3 rd person

Notional person \{Speaker is realized as 1st or 3rd person post-syntactically in English, since the value of semantic person is not strictly associated 
with the morphological information (i.e., grammatical person), in accordance with the generalized geometry in (20). Yet, realizing a distinct person on the reflexive does not change the truth conditions due to the presence of the same notional person that the reflexive possesses. I take the realizations in (25) to be a type of allomorphy, i.e., they are realizations of one person feature value. In other words, the morphosyntactic variation is not attributed to the lack of the syntactic operation for coreference. Instead, the morphosyntactic variation of reflexives is located between morphosyntax and morphophonology at PF, since the generalized feature geometry does not guarantee a one-to-one relation between notional and grammatical person.

The current analysis also accounts for the morphosyntactic variation in (26a), where the head noun is not a 1st person pronoun. The schema of this example is shown in (26b).

(26) a. I am the one who is comfortable with myself/himself.

b. $\operatorname{pronoun}\{$ Speaker, $1 \mathrm{st}\}\left[\mathrm{vP}\left[\mathrm{DP} \operatorname{NP}\{\right.\right.$ Speaker, $1 \mathrm{st}\}\left[\mathrm{CP}_{\mathrm{CP}} \mathrm{RP}_{i}\{\right.$ Speaker,$\emptyset\}$

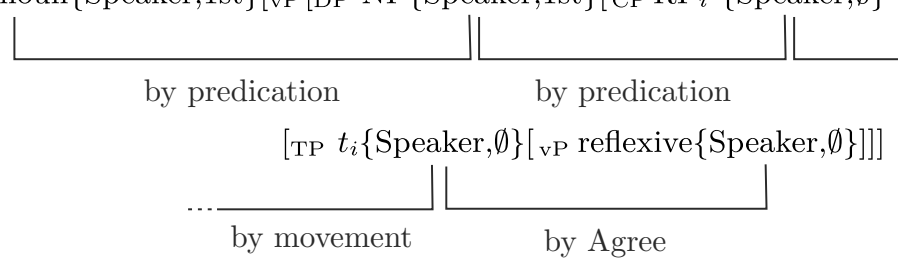

In contrast to the syntactic operations in (24b), in (26b) an additional agreement relation is required via the (regular) predication relation. This is because the predicate in the matrix clause lacks the relevant $\phi$-value, so the pronominal subject Agrees with the predicate in the matrix clause. Once the predicate obtains the $\phi$-value, its value is shared with the reflexive in the embedded clause via the relativized subject in CP and also its lower copy in TP, much like in (24b).

We should notice that the predicate noun the one in (26a) itself does not have a 1st person feature; otherwise the sentences in (27) with the schema shown in (28) would be predicted to be grammatical (Akmajian 1970; 1979; Declerck 1988; den Dikken 2006, among others).

(27) a. *The one that cut myself is only me.

b. *The one who has always kept myself out of trouble is only me.

$(28) *\left[\mathrm{TP}\left[\mathrm{DP}\right.\right.$ the one ( ) [ $\mathrm{CP}_{\mathrm{CP}} \mathrm{RP}_{i}$ ( ) [TP $t_{i}$ ( ) reflexive $\{$ Speaker\}] [ [vP ...me \{Speaker, 1st\}]] 
The sentences in (27) can only receive predicational readings; the specificational readings are impossible because of only. ${ }^{17}$ This indicates that the subjects in these sentences are not inverted from the predicate positions. Crucially, these sentences are ungrammatical when they have a 1st person reflexive in the relative clause. This indicates that the head noun the one itself does not inherently possess $\{$ Speaker, 1 st $\} /\{$ Speaker, $\emptyset\}$ features. Nor does it obtain the person feature locally, since the 1st person pronoun in the predicate position is too far to share the person feature with it. The lack of a local antecedent for the 1st person reflexive induces a violation of Condition A, resulting in ungrammaticality. This shows that the 1st person feature of the reflexive in (26a) comes from the personal pronoun in the matrix clause.

To summarize, I analyzed the relation between syntax and morphology in light of subject-verb agreement and binding agreement in English relatives. I argued that both verbal morphology and reflexives in relative clauses are valued by an element with the person feature in the matrix clause via the mediateion of the relativized subject. Relativized subjects obtain notional person but not grammatical person from the head noun in English. Because of the lack of grammatical person (i.e., morphological information), the verbal morphology is underspecified even after subject-verb agreement, and so is realized as 3rd person post-syntactically, in support of $(3 \mathrm{~b})$. The partial agreement holds of a $3 \mathrm{rd}$ person reflexive in relatives. English also allows reflexives with $\{$ Speaker, $\emptyset\}$ to be realized as 1st person at PF. These featural specifications are attributed to the absence of grammatical person (morphological information). These specifications are tied to language-specific strategies of English at PF.

In the following section I analyze (under)specification of subject-verb agreement in conjunction with binding relations in relative clauses in Bemba and Spanish, and classify three types of morphosyntactic specification for the person feature.

${ }^{17}$ Declerck $(1988,32)$ reports that adding only to the focus (the noun in the predicate position) will block the specificational reading in (ib), in contrast to the sentence in (ia), which is ambiguous:

(i) a. the one who murdered Smith is my neighbor (specificational, predicational) b. the one who murdered Smith is only my neighbor (predicational only) 


\subsection{Three types of morphological varition of the person feature}

I analyzed the relation between syntax and morphology in English relatives by employing the generalized feature geometry for the person feature with Agree in syntax. I argued that English reflexive pronouns with the features $\{$ Speaker, $\emptyset\}$ can be realized as 1st or 3rd person at PF because they have notional person but not grammatical person (morphological information) in syntax. The marriage of the generalized feature geometry with DM provides an interesting testing ground for the present analysis because it predicts that there are languages that exhibit underspecification of the person feature. This way of morphological realization is not uncommon because it falls within the group of mismatches between morphosyntactic and morphophonological realizations listed in (29).

(29) Syntactic features vs. morphological realizations

a. one-to-many relation - allomorphy

b. many-to-one relation - underspecification

The relation between morphosyntactic and morphophonological realization in (29a) is one-to-many, that is, allomophy. The opposite relation in $(29 b)$ is many-to-one with fewer contrasts in the overt form. In other words, in this case we have underspecified vocabulary items or an invariable morphological form spelling out distinct syntactic features. This group is categorized as underspecification. I claim that the pronominal alternations in English relatives are a case of allomorphy because one person feature value is morphologically realized in two ways (30).

(30) The person features of a reflexive and their realization in English relatives

\begin{tabular}{ll}
\hline Syntax & reflexive with $\{$ Speaker- $\emptyset\}$ \\
\hline $\mathrm{PF}$ & ourselves or themselves \\
\hline
\end{tabular}

I argue that a language that displays the second type of featural specification is Bemba, a major Bantu agglutinating language spoken mainly in north-eastern Zambia. Let us look at the basic featural specifications in (31).

(31) a. Néa-àlíí-í-món-à.

SM.1st.c1-PST-self-see-fv

'I saw myself.' 
b. ú-àlíí-í-món-à.

SM.2nd.c1-PST-self-see-fv

'You saw yourself.'

c. á-álíí-í-món-à.

SM.3rd-PST-self-see-fv

'He saw himself.'

(Bemba; Kula 2014, 50)

In regular sentences, the verb exhibits person agreement while the reflexive is the invariable morpheme $-i$ - According to Kula $(2014,3)$, the presence of the reflexive $-i$ - in the verbal complex is readily identified because vowels in the vicinity never fuse in Bemba.

In Bemba reflexives, the verbal morphology is uniformly underspecified (i.e., AAE) regardless what person feature values the head nouns have (32).

(32) a. ni-ne u-u-lee-i-lolesha mu-mira.

COP-1st REL-U-TNS-self-look the mirror

'It is I who is looking at myself (in the mirror).'

b. ni-we u-u-lee-i-lolesha mu-mira.

COP-2nd REL-U-TNS-self-look the mirror

'It is you who is looking at yourself (in the mirror).'

(Bemba; kindly provided to me by Nancy Kula p.c.)

c. u-mulumendo ú-u-ka-belenga ibuku. (*ú-a-ka-belenga) $(=14)$

1-boy REL-U-FUT-read 5book REL-3SG-fut-read

'the boy who will read the book'

The verbal affix $-u$ - after the relative marker is an invariable form, distinct from 3rd person - $a-$. This verbal morphology is the default/neutral form in Bemba (Henderson 2013), similar to 3rd person verbal agreement in English relatives. This indicates that relativized subjects in Bemba obtain notional person but not grammatical person, inducing the AAE in Bemba. However, unlike in English, the morphology of Bemba reflexives appearing in the verbal complex also shows the invariant morphological form, regardless of the person value of the head noun(32a,b). I propose that the relation between syntax and morphology for the Bemba reflexives is underspecification (33). ${ }^{18}$

18 The identical morphology of reflexives results from a lexical gap in Bemba. However, thanks to the syntactic process of sharing the notional person value, the conferential readings are possible in simple sentences and reflexives independently of the presence/ absence of verbal morphology and the identical reflexive marker. 
(33) The person features of reflexives and their realization in Bemba

\begin{tabular}{lcc}
\hline Syntax & reflexive with $\{$ Speaker- $\emptyset\}$ & reflexive with $\{$ Speaker-1st $\}$ \\
\hline $\mathrm{PF}$ & $-i-$ & $-i-$ \\
\hline
\end{tabular}

The morphology for the reflexive associated with the distinct person feature values is uniformly realized as $-i$ - This realization is taken as underspecified (many-to-one relation).

In the previous paragraphs I have discussed two types of relations between syntax and morphology of person features in English and Bemba relatives. However, there is another relation, too, exhibited by Spanish, as Sornicola $(1988,351)$ observes (34).

(34) a. Soy yo quien/el que me lavo.

be-1st I who/the-one that REFL-1st wash-1st

b. Soy yo quien/el que se lava.

be-1st I who/the-one that REFL-3rd wash-3rd

c. Eres tu quien/el que te lavas.

be-2nd you who/the-one that REFL-2nd wash-2nd

d. Eres tu quien/el que se lava.

be-2nd you who/the-one that REFL-3rd wash-3rd

When the head noun is a singular 1st or 2nd person pronoun, the verbal morphology may or may not show the AAE. Moreover, Spanish exhibits binding alternations, similar to those in English relatives. According to Sornicola (1988), Standard French and Italian also show the same variation in both subject-verb agreement and binding agreement.

However, the native speakers of Spanish that I consulted do not accept any mismatch in the person feature between subject-verb agreement and binding agreement (35).

(35) a. * Soy yo quien/el que me lava.

be-1st I who/the-one that REFL-1st wash-3rd

b. ${ }^{*}$ Soy yo quien/el que se lavo.

be-1st I who/the-one that REFL-3rd wash-1st

c. ${ }^{*}$ Eres tu quien/el que te lava.

be-2nd you who/the-one that REFL-2nd wash-3rd 
d. *Eres tu quien/el que se lavas.

be-2nd you who/the-one that REFL-3rd wash-2nd

This shows that unlike in Bemba and in English, notional person and grammatical person shared via Agree are in a one-to-one relation in Spanish.

(36) The person features of reflexives and their realization in Spanish relatives

\begin{tabular}{lcc}
\hline Syntax & reflexive with $\{$ Speaker-1st $\}$ & reflexive with $\{$ Speaker- $\emptyset\}$ \\
\hline $\mathrm{PF}$ & $m e$ & se \\
\hline
\end{tabular}

I examined the three types of relations between syntax and morphology in relative clauses in English, Bemba, and Spanish and argued that an Agree relation is called for as a feature-sharing operation. Yet the Agree operation does not necessarily share both notional and grammatical person, which leads to morphosyntactic variation. ${ }^{19}$ English and Bemba relativized subjects only obtain notional person but not grammatical person and thus verbal agreement in relative clauses has an invariable form, in support of the perspective in $(3 \mathrm{~b})$. However, the realization of reflexives differs in these two languages: English shows allomophy (i.e., pronominal alternations) whereas Bemba displays underspecification, although the value of the person feature is the same. On the other hand, Spanish relativized subjects (optionally) obtain both notional and grammatical person. Thus, verbal morphology as well as reflexives in relative clauses exhibit agreement uniformly; otherwise 3rd person is realized in both subject-verb agreement and binding relations.

\section{Conclusion and implications}

I examined person agreement and its morphological (under)specification in English, Bemba, and Spanish relative clauses. When 1st or 2nd person pronouns appear in the matrix clause, English relatives uniformly exhibit the 3rd person verbal morphology, while admitting 1st/2nd as well as 3rd person reflexives at the same time. Having argued that 3rd person is an invariable form of the verbal morphology in English, I applied three major AAE analyses to English relative clauses and showed that they fail to account for the pronominal alternations. By way of an alternative, I gen-

${ }^{19}$ I cannot offer an analysis of the AAE in the negation contexts of Ibibio here; I leave this for future research. 
eralized Harley and Ritter's (2002) feature geometry of the person feature to non-personal pronouns and proposed that the person feature should be split into two types: notional and grammatical person. I argued that relative pronouns may get partial valuation of the person feature via Agree due to language-specific preferences, since notional and grammatical person are not uniformly in a one-to-one relation. This partial sharing of the person feature with relative pronouns leads to three types of morphosyntactic variation in English, Bemba, and Spanish relative clauses.

If the current argument is on the right track, various featural specifications such as AAEs and the binding alternations in relative clauses result from the absence of a one-to-one relation between syntax and morphology cross-linguistically, even though the operation for $\phi$-agreement is the same in narrow syntax. This indicates that referential and morphological (under)specifications are kept separate under the constraints of Agree.

The present analysis of the person feature explored two logical possibilities in $(3 \mathrm{a}, \mathrm{b})$ as the analysis of AAE and it supports the statement in $(3 \mathrm{~b})$. The current analysis may also account for other constructions because relative pronouns are not the only lexical items whose forms remain unchanged regardless of distinct person feature values. As Collins and Postal (2012) observe, singular English definite DPs in the imposter use uniformly trigger 3rd person verbal agreement while at the same time exhibiting pronominal alternations in binding. These agreement phenomena are compatible with those of relatives in the same language. Moreover, a modified personal pronoun also exhibits the same agreement pattern, as in the new me is/*am proud of myself/himself (Bernstein 2008). If he same agreement mismatches are also found beyond relative clauses, then those mismatches may serve as arguments in favor of the current analysis.

The present argument also suggests that AAEs are not caused by subject extraction or any kind of empty category, such as a movement trace, being present in the subject position. Instead, wh-subjects that lack grammatical person make the verbal morphology underspecified and so realized as invariable forms at PF. However, interrogative and relativized subjects are different in terms of person agreement: the latter may obtain the person feature syntactically, while the former cannot. Thus, Ouhalla's (1993) widely acknowledged method of treating interrogative and relativized subjects on a par may not be legitimate for studies of AAEs, since there are languages (e.g., English and Spanish) that show 1st or 2nd person agreement with relativized subjects but not with wh-subjects. 


\section{Acknowledgements}

In trying to bring this paper to its present shape, I have benefitied considerably from discussions with Dorian Roehrs and Marcel den Dikken. I have also benefited from helpful comments from two reviewers of this journal.

\section{References}

Adger, David. 2003. Core syntax. A minimalist approach. Oxford: Oxford University Press.

Adger, David. 2011. Bare resumptives. In A. Rouveret (ed.) Resumptive pronouns at the interfaces. Amsterdam \& Philadelphia: John Benjamins. 343-365.

Akmajian, Adrian. 1970. Aspects of the grammar of focus in English. Doctoral dissertation. MIT.

Akmajian, Adrian. 1979. On deriving cleft sentences from pseudocleft sentences. Linguistic Inquiry 1. 149-168.

Baker, Mark. C. 2008. On the nature of the antiagreement effect: Evidence from wh-in-situ in Ibibio. Linguistic Inquiry 39. 615-632.

Baker, Mark. C. 2011. When agreement is for number and gender but not person. Natural Language \& Linguistic Theory 29. 875-915.

Béjar, Susana and Milan Rezac. 2009. Cyclic Agree. Linguistic Inquiry 40. 35-73.

Bernstein, Judy B. 2008. The expression of third person in older and contemporary varieties of English. English Studies 89. 571-586.

Bianchi, Valentina. 1999. Consequences of antisymmetry: Headed relative clauses. Berlin \& New York: Mouton de Gruyter.

Bianchi, Valentina. 2000. The raising analysis of relative clauses: A reply to Borsley. Linguistic Inquiry 31. 123-40.

Bobaljik, Jonathan. 2002. A-chains at the PF-interface: Copies and "covert" movement. Natural Language \& Linguistic Theory 20. 157-267.

Boef, Eefje. 2012. Doubling in relative clauses: Aspects of morphosyntactic microvariation in Dutch. Doctoral dissertation. Utrecht University.

Borsely, Robert and Janig Stephens. 1989. Agreement and the position of subjects in Breton. Natural Llanguage and Linguistic Theory 7. 407-428.

Bošković, Željko. 2014. Now I'm a phase, now I'm not a phase: On the variability of phases with extraction and ellipsis. Linguistic Inquiry 48. 27-89.

Brandi, Luciana and Patrizia Cordin. 1989. Two Italian dialects and the null-subject parameter. In O. Jaeggli and K. Safir (eds.) The null subject parameter. Dordrecht: Kluwer. 111-142.

Canac-Marquis, Réjean. 2005. Phases and binding of reflexives and pronouns in English. In C. Gurski (ed.) Proceedings of the Canadian Linguistic Association Annual Conference. Ontario: University of Western Ontario. 482-502.

Cheng, Lisa. 2006. Decomposing Bantu relatives. NELS 36. 197-216.

Chomsky, Noam. 1977. On wh-movement. In P. W. Culicover, T. Wasow and A. Akmajian (eds.) Formal syntax. New York: Academic Press. 71-132. 
Chomsky, Noam. 1993. A minimalist program for linguistic theory. In Hale \& Keyser (1993, 1-52).

Chomsky, Noam. 2000. Minimalist inquiries: The framework. In R. Martin, D. Michaels and J. Uriagereka (eds.) Step by step: Essays on minimalist syntax in honor of Howard Lasnik. Cambridge, MA: MIT Press. 89-155.

Chomsky, Noam. 2001. Derivation by phase. In M. Kenstowicz (ed.) Ken Hale: A life in language. Cambridge, MA: MIT Press. 1-52.

Chomsky, Noam. 2007. Approaching UG from below. In U. Sauerland and H.-M. Gärtner (eds.) Interfaces + recursion = language? Chomsky's minimalism and the view from syntax-semantics. Berlin \& New York: Mouton de Gruyter. 1-29.

Chomsky, Noam. 2008. On phases. In R. Freidin, C. P. Otero and M. L. Zubizarreta (eds.) Foundational issues in linguistic theory. Essays in honor of Jean-Roger Vergnaud. Cambridge, MA: MIT Press. 134-166.

Chomsky, Noam and Howard Lasnik. 1993. The theory of principles and parameters. In J. Jacobs, A. von Stechow, W. Sternefeld and T. Vennemann (eds.) Syntax: An international handbook of contemporary research. Vol. 1. Berlin \& New York: Mouton de Gruyter. 506-569.

Chung, Sandra. 1998. The design of agreement: Evidence from Chamorro. Chicago: The University of Chicago Press.

Collins, Chris. 2014. Cross-linguistic studies of imposters and pronominal agreement. Oxford: Oxford University Press.

Collins, Collins and Paul Postal. 2012. Imposters: A study of pronominal agreement. Cambridge, MA: MIT Press.

Declerck, Renaat. 1988. Studies on copular sentences, clefts and pseudoclefts. Leuven/ Dordrecht: Leuven University Press/Foris.

Despić, Miloje. 2015. Phases, reflexives and definiteness. Syntax 18. 201-234.

Diercks, Michael. 2010. Agreement with subjects in Lubukusu. Doctoral dissertation. Georgetown University.

Diercks, Michael. 2013. Indirect Agree in Lubukusu complementizer agreement. Natural Language \& Linguistic Theory 31. 357-407.

Dikken, Marcel den. 2006. Specificational copular sentences and pseudoclefts. In M. Everaert and H. van Riemsdijk (eds.) The Blackwell companion to syntax. Malden, MA \& Oxford: Blackwell. 292-409.

Dikken, Marcel den. 2007. Phase extension: Contours of a theory of the role of head movement in phrasal extraction. Theoretical Linguistics 33. 1-41.

Essien, Okon. 1990. A grammar of the Ibibio language. Ibadan: University Press.

Fischer, Silke. 2004. Optimal Binding. Natural Language \& Linguistic Theory 22. 481-526.

Fischer, Silke. 2006. Matrix unloaded: Binding in a local derivational approach. Linguistics: An Interdisciplinary Journal of the Language Sciences 44. 913-935.

Fox, Danny and Jon Nissenbaum. 1999. Extraposition and scope: A case for overt QR. In S. Bird, A. Carnie, J. Haugen and P. Norquest (eds.) Proceedings of the 18th West Coast Conference on Formal Linguistics. Somerville, MA: Cascadilla Press. 132-144.

Furuya, Kaori. 2009. The DP hypothesis through the lens of Japanese nominal collocation constructions. Doctoral dissertation. City University of New York. 
Furuya, Kaori. 2016a. Person agreement in restrictive relative clauses: Head external analysis verses head internal analysis. Manuscript.

Furuya, Kaori. 2016b. PRO and (under)specification of person in imposter constructions. Theory and Practice in Language Studies 6. 1723-1731.

Furuya, Kaori. 2017. Adjunct control and agreement. Manuscript.

Georgopoulos, Carol. 1991. Syntactic variables: Resumptive pronouns and A' binding in Palauan. Dordrecht: Kluwer.

Grohmann, Kleanthes K. 2003. Prolific domains: On the anti-locality of movement dependencies. Amsterdam \& Philadelphia: John Benjamins.

Hale, Kenneth and Samuel Jay Keyser (eds.). 1993. The view from building 20. Essays in linguistics in honor of Sylvain Bromberger. Cambridge, MA: MIT Press.

Halle, Morris and Alec Marantz. 1993. Distributed morphology and the pieces of inflection. In Hale \& Keyser (1993, 111-176).

Halle, Morris and Alec Marantz. 1994. Some key features of Distributed Morphology. In A. Carnie and H. Harley (eds.) MIT Working Papers in Linguistics 21: Papers on phonology and morphology. Cambridge, MA: MIT Press. 275-88.

Harley, Heidi and Elizabeth Ritter. 2002. Person and number in pronouns: A featuregeometric analysis. Language 78. 482-526.

Heck, Fabian and Juan Cuartero. 2008. Long distance agreement in relative clauses. Varieties of Competition 47. 13-48.

Henderson, Brent. 2009. Anti-agreement and [Person] in Bantu. In M. Matondo, F. McLaughlin and E. Potsdam (eds.) Selected proceedings of the 38th Annual Conference on African Linguistics: Linguistic Theory and African Language Documentation. Somerville, MA: Cascadilla Press. 173-181.

Henderson, Brent. 2013. Agreement and person in anti-agreement. Natural Language \& Linguistic Theory 31. 453-481.

Hendrick, Randall. 1988. Anaphora in Celtic and Universal Grammar. Dodrecht: Kluwer.

Hicks, Glyn. 2009. The derivation of anaphoric relations. Amsterdam \& Philadelphia: John Benjamins.

Kayne, Richard S. 1994. The antisymmetry of syntax. Cambridge, MA: MIT Press.

Kayne, Richard S. 2000. Parameters and universals. Oxford: Oxford University Press.

Kimball, John and Judith Aissen. 1971. I think, you think, he think. Linguistic Inquiry 2. 241-246.

Kinyalolo, Kasangati. 1991. Syntactic dependencies and the SPEC-head agreement hypothesis in Kilega. Doctoral dissertation. UCLA.

Kobele, Gregory. 2010. A formal foundation for A and A-bar movement in the Minimalist Program. In C. Ebert, G. Jäger and J. Michaelis (eds.) Lecture notes in computer science. Berlin: Springer. 145-159.

Kornfilt, Jaklin. 1991. Some current issues in Turkish syntax. In H. Boeschoten and L. Verhoeven (eds.) Turkish linguistics today. Brill: Brill. 60-92.

Kratzer, Angelika. 2009. Making a pronoun: Fake indexicals as windows into the properties of pronouns. Linguistic Inquiry 48. 187-237.

Kula, Nancy. 2014. Anaphora in the African languages - Questionnaire for language consultants. http://www.africananaphora.rutgers.edu/bemba-casemenu-203 
Landau, Idan. . 2000. Elements of Control: Structure and meaning in infinitival constructions. Dodrecht: Kluwer.

Landau, Idan. 2004. The scale of finiteness and the calculus of control. Natural Language \& Linguistic Theory 22. 811-877.

Landau, Idan. 2013. Control in generative grammar: A research companion. Cambridge: Cambridge University Press.

Landau, Idan. 2015. A two-tiered theory of control. Cambridge, MA: MIT Press.

Lee-Schoenfeld, Vera. 2008. Binding, phases, and locality. Syntax 11. 281-298.

McCloskey, James. 1990. Resumptive pronouns, A'-binding, and levels of representation in Irish. In R. Hendrick (ed.) Syntax and semantics: The syntax of the Modern Celtic languages. New York: Academic Press. 199-238.

McGinnis, Martha. 2004. Lethal ambiguity. Linguistic Inquiry 35. 47-95.

Morita, Hisashi. 2009. Covert pied-piping in Japanese WH-questions. English Linguistics 26. 374-393.

Munakata, Takashi. 2006. Paper presented at Workshop in Altaic Formal Linguistics 3. Intermediate Agree: Complementizer as a Bridge.

Nelson, Gerald. 1997. Cleft constructions in spoken and written English. Journal of English Linguistics 25. 340-348.

Nevins, Andrew. 2007. The representation of third person and its consequences for personcase effects. Natural Language \& Linguistic Theory 25. 273-313.

Nevins, Andrew. 2011. Multiple agree with clitics: Person complementarity vs. omnivorous number. Natural Language \& Linguistic Theory 29. 939-971.

O'Herin, Brian. 2002. Case and agreement in Abaza. Arlington, TX: University of Texas Press.

Ouali, Hamid. 2008. On C-to-T phi-feature transfer: The nature of agreement and antiagreement in Berber. In R. D'Alessandro, S. Fischer and G. H. Hrafnbjargarson (eds.) Agreement restrictions. Berlin \& New York: Mouton de Gruyter. 159-180.

Ouhalla, Jamal. 1993. Subject extraction, negation and the anti-agreement effect. Natural Language \& Linguistic Theory 11. 477-518.

Ouhalla, Jamal. 2005. Agreement feature, agreement, and anti-agreement. Natural Language \& Linguistic Theory 23. 655-686.

Perlmutter, David M. 1972. Evidence for shadow pronouns in French relativization. In P. M. Peranteau, J. N. Levi and G. C. Phares (eds.) The Chicago which hunt: Papers from the Relative Clause Festival. Chicago: Chicago Linguistic Society. 73-105.

Pesetsky, David and Esther Torrego. 2007. The syntax of valuation and the interpretability of features. In S. Karimi, V. Samiian and W. K. Wilkins (eds.) Phrasal and clausal architecture. Syntactic derivation and interpretation. Amsterdam \& Philadelphia: John Benjamins. 262-294.

Phillips, Colin. 1996. Order and structure. Doctoral dissertation. MIT.

Quicoli, Carlos A. 2008. Anaphora by phase. Syntax 11. 299-329.

Rackowski, Andrea and Norvin Richards. 2005. Phase edge and extraction: A Tagalog case study. Linguistic Inquiry 36. 565-599.

Reeve, Matthew. 2011. The syntactic structure of English clefts. Lingua 121. 142-171.

Reuland, Eric. 2011. Anaphora and language design. Cambridge, MA: MIT Press. 
Rooryck, Johann and Guido Vanden Wyngaerd. 2011. Dissolving binding theory. Oxford: Oxford University Press.

Ross, John R. 1970. On declarative sentences. In R. A. Jacobs and P. S. Rosenbaum (eds.) Readings in English transformational grammar. Waltham MA: Blaisdell. 222-272.

Safir, Ken. 2014. One true anaphor. Linguistic Inquiry 45. 91-124.

Schachter, Paul. 1973. Focus and relativization. Language 49. 19-46.

Schneider-Zioga, Patricia. 1995. Specifier/head agreement in Kinande. Cahiers Linguistique D'Ottawa 23. 67-96.

Schneider-Zioga, Patricia. 2000. Anti-agreement and the fine structure of the left edge. In R. Ai, F. del Gobbo, M. Irie and H. Ono (eds.) Working papers in linguistics 6 . Irvine, CA: Department of Linguistics, University of California. 94-114.

Schneider-Zioga, Patricia. 2007. Anti-agreement, anti-locality and minimality: The syntax of dislocated subjects. Natural Language \& Linguistic Theory 25. 403-446.

Sornicola, Rosanna. 1988. It-clefts and wh-clefts: Two awkward sentence types. Journal of Linguistics 24. 343-379.

Urk, Coppe van and Norvin Richards. 2015. Two components of long-distance extraction: Successive cyclicity in Dinka. Linguistic Inquiry 46. 111-155.

Vinokurova, Nadezhda. 2009. On raising and proleptic objects in Sakha. Manuscript. Rutgers University and State University of Yakutsk.

Vries, Mark de. 2002. The syntax of relativization. Utrecht: LOT.

Watanabe, Akira. 2006. The pied-piper feature. In L. L.-S. Cheng and N. Corver (eds.) Wh-movement: Moving on. Cambridge, MA: MIT Press. 47-70.

Zwart, Jan-Wouter. 2000. A head raising analysis of relative clauses in Dutch. In A. Alexiadou, P. Law, A. Meinunger and C. Wilder (eds.) The syntax of relative clauses. Amsterdam \& Philadelphia: John Benjamins. 349-386. 